\title{
Poder de negociación y distribución social de capacidades para la nacionalización de la vida económica: ¿por qué la renta básica es un proyecto democratizador?*
}

\author{
Bargaining power and social distribution of capacities for \\ the nationalisation of economic life: why basic income is a \\ democratizing project?
}

DAVID CASASSAS**

Resumen: Este artículo analiza en cuatro tiempos el potencial del acceso incondicional a recursos en la conformación de relaciones (re)productivas libres. En primer lugar, defiende una noción de democracia (económica) que exige la presencia de recursos incondicionalmente predistribuidos. En segundo lugar, explora el vínculo entre predistribución y poder de negociación. En tercer lugar, presenta el derecho a la existencia como condición para una cooperación social efectiva que merezca la pena ser cuidada. En cuarto lugar, discute el papel de la renta básica en procesos de nacionalización de la vida económica entendidos como expresión de la voluntad democrática de la ciudadanía.

Palabras clave: renta básica, predistribución, poder de negociación, cooperación social, nacionalización, democracia económica

\begin{abstract}
This article analyses in four stages the potential of unconditional access to resources in the conformation of free (re)productive relations. Firstly, it defends a notion of (economic) democracy requiring the presence of unconditionally predistributed resources. Secondly, it explores the link between predistribution and bargaining power. Thirdly, it presents the right to existence as a condition for an effective social cooperation worth taking care of. Fourthly, it discusses the role of basic income in processes of nationalisation of economic life understood as the expression of the democratic will of citizenry.
\end{abstract}

Keywords: basic income, predistribution, bargaining power, social cooperation, nationalisation, economic democracy

Recibido: 21/05/2020. Aceptado: 23/06/2020. Cómo citar este articulo: Casassas, D. (2020). Poder de negociación y distribución social de capacidades para la nacionalización de la vida económica: ¿por qué la renta básica es un proyecto democratizador? Daimon. Revista Internacional de Filosofía, (81), 215-229. https://doi.org/10.6018/ daimon.428911

* Trabajo realizado en el marco del proyecto PGC2018-094324-B-I00 (MCIU/AEI/FEDER, UE). Julio MartínezCava, David Guerrero, Jordi Mundó y Simon Birnbaum aportaron valiosos comentarios que agradezco enormemente.

** Universidad de Barcelona, Profesor Agregado. E-mail: dcasassas@ub.edu. Líneas de investigación: historia de las ideas, teoría social y política, republicanismo, renta básica. Publicaciones recientes: Libertad incondicional. La renta básica en la revolución democrática, Barcelona: Paidós, 2018; «Republicanism and the political economy of democracy», European Journal of Social Theory, 19(2), pp. 283-300, 2016 (con Jurgen De Wispelaere). 
Imaginemos un centro social ocupado; un hogar cualquiera; una cooperativa del sector agroalimentario; una sociedad anónima en el ámbito de las nuevas tecnologías; un establecimiento comercial con una decena de trabajadores a sueldo; imaginemos una asamblea de barrio orientada a la intervención comunitaria para la garantía de ciertos servicios sociales; imaginemos una revista o proyecto editorial colectivo; imaginemos un sector productivo entero: el del agua o el de la energía, pongamos. Pues bien, ¿cómo conceptualizar la democracia en cualquiera de estos entornos? O, si lo preferimos así, ¿cómo entender un proceso de democratización de tales espacios? ¿En qué sentido podemos decir que quienes participan en ellos gozan de los niveles de soberanía individual y colectiva necesarios para poder co-determinar su naturaleza y funcionamiento? ¿Hasta qué punto podemos suponer que la concatenación de actos y procesos democratizadores en todos estos espacios de trabajo -y en cualquier otro- puede conllevar transformaciones sistémicas en términos de sometimiento a control colectivo de la vida social y económica toda?

Este texto aspira a arrojar luz sobre todas estas cuestiones. Con la propuesta de la renta básica como telón de fondo, este trabajo muestra cómo el acceso universal e incondicional a ciertos conjuntos de recursos público-comunes -entre ellos, la renta básica, pero también prestaciones en especie-, gracias al poder de negociación que confiere, permite contradecir las dinámicas desposeedoras propias del capitalismo, tan añejas y, sin embargo, con tanta capacidad para metamorfosearse y reproducirse a lo largo del tiempo (Harvey, 2003), y, a partir de ahí, abrir las puertas a formas de trabajo y de vida respetuosas con la autonomía de todas las partes implicadas.

Para ello, se explorarán cuatro conjuntos de cuestiones estrechamente entrelazadas. En primer lugar, se defenderá una noción de democracia (económica) que exige la presencia de recursos incondicionalmente "predistribuidos" en la conformación de las relaciones sociales. En segundo lugar, se analizará el vínculo entre "predistribución” y poder de negociación, con la mirada puesta en los factores determinantes de dicho poder de negociación y en el "poder social" que éste puede llegar a otorgar en punto a articular "vidas pluriactivas" donde, al decir de Marx y Engels (1970, 34), "cada individuo [o grupo] no [tenga] acotado un círculo exclusivo de actividades, sino que [pueda] desarrollar sus aptitudes en la rama que mejor le parezca". En tercer lugar, se presentará la garantía del derecho a la existencia que viene dada por el acceso incondicional a recursos -entre ellos, una renta básica- como el punto de partida de una cooperación social en la que el compromiso con respecto al cuidado de la esencial interdependencia que vertebra las vidas humanas adquiera pleno sentido. En otras palabras, se pensará el espacio de posibles deberes cívicos y "prosociales" en el seno de sociedades en las que se haya instituido el derecho incondicional a la existencia. Finalmente, en cuarto y último lugar, cerrará este ensayo una reflexión sobre el potencial democratizador que una idea de "nacionalización" de la vida económica como expresión de la soberanía popular puede llevar de la mano, y sobre el papel de medidas como la renta básica en términos de distribución social de capacidades para el logro de dicha "nacionalización" o, lo que es lo mismo, para la extensión social de vías para la configuración de las relaciones de trabajo efectivamente arraigadas a la voluntad del demos. 


\section{Incondicionalidad y capacidades para la democracia}

Iniciamos el recorrido con una aproximación conceptual a la democracia (económica) que nos obliga a asociarla a una capacidad cuatripartita o, si se prefiere, a cuatro capacidades estrechamente vinculadas entre sí1.

En primer lugar, democracia (económica) significa capacidad de "entrar" en relaciones (re)productivas deseadas, que ofrezcan un entorno y unos productos finales, materiales e inmateriales, que los actores puedan sentir como propios, como piezas de una trayectoria autónomamente escogida. Como se puede deducir, esa posibilidad de "entrar" exige el poder rechazar lo que no se desea e incluso se estima dañino: se trata, por lo tanto, de poder pronunciar ciertos "noes" (Widerquist, 2013) que abran las puertas a muchos "síes" a formas de trabajo, remunerado o no -y, dentro del remunerado, asalariado o no-, que también se quisiera pronunciar. Ni que decir tiene, dicho ejercicio de "entrar (en ciertos espacios) dejando previamente de entrar (en otros espacios)" se hace enormemente difícil cuando los actores sociales operan en condiciones de desposesión, cuando el acceso a recursos depende de los azares y vaivenes propios de los tornadizos mercados de trabajo, en los que la seguridad socioeconómica queda a merced de decisiones y circunstancias que escapan a su control. En cambio, el goce incondicional de recursos otorga a individuos y grupos el margen de maniobra necesario para evaluar, lejos del "frenesí y la extravagancia propios de los desesperados" que Adam Smith $(1981,84-5)$ asociaba a la condición de los desposeídos, qué puertas se quieren abrir y qué alternativas se decide dejar por el camino.

En segundo lugar, democracia (económica) significa capacidad de, una vez "dentro", hacer oír nuestra "voz", de participar de forma efectiva en los procesos decisionales en los que se determinan la naturaleza y el funcionamiento de las relaciones (re)productivas. Pues bien, en este punto, la obra de Albert Hirschman (1970) resulta altamente esclarecedora: la capacidad para la "voz" -asegura Hirschman- se erosiona en aquellos contextos en los que no existe, para ciertos actores, opción de "salida", pues, en tales situaciones, la otra parte de la contienda, sabedora de cuán necesaria resulta esa relación para sus adversarios, se sentirá con fuerza para imponer las condiciones que le interesen. En efecto, es necesario poder "salir" -o poder amenazar de forma creíble con hacerlo- para que la otra parte, consciente del riesgo real de ruptura de esa relación, llegue a tomarse en serio los deseos y reivindicaciones de quienes se muestran disconformes y, en definitiva, se disponga escuchar su "voz". En este punto, la presencia de recursos incondicionales no obliga a la "salida" de las relaciones (re)productivas -tampoco el derecho al divorcio obliga a divorciarse-, pero, otorgando la posibilidad de "salir", refuerza la opción de la "voz" para amplias capas de la población, hoy obligadas a agachar la cabeza y guardar silencio.

En tercer lugar, democracia (económica) significa capacidad para "salir" de forma efectiva, para el "divorcio" de relaciones (re)productivas, cuando éstas se muestran abiertamente insatisfactorias, abiertamente lesivas de la libertad y de la dignidad de alguna(s) parte(s). Pero, nuevamente, dicha opción de "salir" exige una "posición de retirada" o "fallback position", esto es, un conjunto de recursos que garanticen que ese rompimiento de relaciones

1 Para un amplio análisis de estas cuatro capacidades que, además, las pone en relación con la preceptiva éticopolítica republicana, véase Casassas $(2016,2018)$. 
no va a dejar materialmente desamparados a quienes opten por dar ese paso: se necesita un colchón, una red de seguridad de carácter incondicional que habilite de manera efectiva la posibilidad de la salida. Sin ello, dicha posibilidad se convierte en un mero artificio retórico o en una anécdota reservada a un puñado de incautos cargados de voluntarismo ${ }^{2}$.

En cuarto lugar, democracia (económica) significa capacidad de "reiniciar" con sentido y posibilidades de éxito una vida (re)productiva dada, sea porque hayamos caído y nos hallemos en una situación de insolvencia que necesitemos revertir, sea porque, sencillamente, aspiremos a un cambio de timón para nuestra trayectoria. Al fin y al cabo, el "derecho" a segundas, terceras y ulteriores oportunidades, todo ello en el contexto de vidas regidas por dosis nada negligibles de ensayo y error, es algo de lo que ya goza una parte minoritaria de la población. ¿Es concebible la posibilidad de universalizar dicha facultad, que hoy constituye un privilegio, para hacer de ella, precisamente, un derecho efectivo al alance de todos? La hipótesis de trabajo en este punto es que recursos incondicionalmente garantizados no son sólo "recursos" -en particular, la renta básica no es sólo "cash"-, sino que, como veremos a continuación, dichos recursos se convierten, gracias al poder de negociación que confieren, en palancas de activación de flujos de renovada actividad que, de otro modo, se perdería por el camino.

Es por todo ello por lo que cabe situar el proyecto de la renta básica en el marco de estrategias "predistributivas" capaces de trascender las lógicas meramente asistencialistas y de blindar ex-ante, desde "el inicio" de los procesos de interacción social (O'Neill y Williamson, 2012; Rawls, 2001), unos estatus de invulnerabilidad social que permitan la emergencia de una interdependencia realmente democrática que, por serlo, excluya cualquier forma de subordinación y de (auto)censura ${ }^{3}$ y capacite a individuos y grupos para transportar actividades y relaciones sociales a aquellos espacios y entornos, mercantiles o no, en los que genuinamente deseen situar sus vidas.

Mucho se ha escrito sobre igualitarismo predistributivo (Barragué, 2017; Thomas, 2016). Lo importante en este punto consiste en distinguir entre aproximaciones "moderadas" y aproximaciones "emancipatorias" a la cuestión de la predistribución (Casassas, 2018,

2 En este punto, conviene prestar atención a la advertencia que lanzan Birnbaum y De Wispelaere (2016, 2020), quienes aseguran que no vale "cualquier forma de salir", que salir "de cualquier manera" puede situarnos en escenarios poco aptos para la extensión de la libertad efectiva y para la democratización de las relaciones sociales. En efecto, salir de un edificio en llamas puede resultar de lo más sensato -sin duda, constituye esta una opción mucho menos aciaga que el tener que permanecer en él por carecer de puerta o ventana de emergencia-, pero salir de estampida de un edificio en llamas puede situarnos en un territorio virtualmente hecho cenizas en el que resulte harto difícil que vuelvan a aparecer brotes verdes. Por ello, si de lo que se trata es de evaluar el potencial liberador de la posibilidad de salir, es preciso tomar en consideración la situación socio-institucional de quienes puedan optar por salir: ¿cuentan con fomento y regulación estatal del posible tránsito hacia nuevas formas de trabajo, remunerado o no? ¿Se ven acompañados por dispositivos para el trabajo social de los problemas en que se hallan? ¿Cuentan, en definitiva, con verdaderas oportunidades para retomar su camino? Y, finalmente -y esta es una cuestión señalada por Alex Gourvevitch (2016)-, ¿existe una cultura cívico-política preexistente o en proceso de formación sobre qué puede significar trabajar en condiciones de libertad, una cultura que, como la de los "labor republicans" de los Estados Unidos del siglo XIX (Gourevitch, 2014), pueda dotar de sentido emancipatorio y orientar de un modo institucional y organizativamente fértil la acción de quienes intenten y tal vez logren "salir" de relaciones de trabajo que estimen inaceptables?

3 El lenguaje y el análisis republicanos de lo que se plantea resulta evidente. Véanse Domènech (2004), Pettit (2012) y, en la estela de ambos, Casassas (2018). 
2020a). Las primeras, que podemos asociar a autores como Hacker (2011) o Kenworthy (2013), tienden a tomar el capitalismo, empezando por sus mercados de trabajo, como un hecho consumado, como una realidad que no puede ser cuestionada y menos subvertida a través de grandes procesos de distribución de la riqueza y de la propiedad. A partir de ahí, quienes hacen suya esta visión "moderada" de la predistribución señalan la necesidad de introducir marcos reguladores y medidas de protección que hagan de la existencia dentro de los perímetros de esos inevitables mercados de trabajo capitalistas algo menos áspero: fortalecimiento de los sindicatos, incremento del salario mínimo, desegmentación del mercado de trabajo, repartos más justos de los beneficios empresariales y, en definitiva, aumento del empleo.

En cambio, la aproximación "emancipatoria" a la predistribución -pensemos en la obra de O’Neill y Williamson (2012), de Stuart White $(2012,2020)$ o del propio John Rawls (2001) - apunta a la necesidad de que, gracias a la incondicionalidad de recursos públicocomunes conferidos como garantía del derecho a una vida digna ${ }^{4}$, opere un distanciamiento crítico con respecto a la institucionalidad capitalista -empezando por sus mercados de trabajo- que permita y favorezca configuraciones de las relaciones (re)productivas, distributivas y de propiedad quizás alternativas a las que encontramos bajo dicha formación social. Todo ello, no tanto porque sea necesario desmercantilizar la fuerza de trabajo -esto es, "divorciarnos" de quienes nos contratan en los mercados de trabajo-, sino porque resulta crucial poder desmercantilizar la fuerza de trabajo -esto es, "podernos divorciar" de quienes nos contratan-. Muy probablemente, dicha posibilidad de sustraer recursos y actividades de los mercados constituya la principal variable para la medición de los grados de libertad y democracia de los que gocemos en el seno de sociedades contemporáneas.

\section{Renta básica, poder de negociación y economía política de los encargos recíprocos}

Dotados del poder de negociación que confiere el acceso a recursos incondicionales -entre ellos, una renta básica-, individuos y grupos pueden verse capacitados para rechazar aquellas formas de división social, sexual y/o étnica del trabajo en las que hoy se ven atrapados -recordemos que hay división social, sexual o étnica del trabajo cuando hay procesos de asignación de tareas en función de la extracción social, de la identidad de género y/o de la procedencia geográfica y cultural de las personas, lo que normalmente condena a quienes caen dentro de grupos minorizados a la realización de las tareas más desagradables y/o menos valoradas-. En efecto, dotados del poder de negociación que confiere el acceso a recursos incondicionales, individuos y grupos pueden tender a sugerir y, si es preciso, forzar un reparto de tareas acorde con (o más respetuoso de) los deseos, inclinaciones y talentos de cada cual -obviamente, no se sugiere con esto que el objetivo tenga que ser la plena (y universal) externalización de una supuesta identidad personal y creativa-laboral pétreamente inscrita en la arquitectura cognitiva de cada individuo: el mundo (del trabajo) dista de ser un rompecabezas de solución única y unívoca, lo que tampoco ha de significar que las piezas

4 Pero ¿qué recursos exactamente? Este artículo se centra en la renta básica, pero anima a concebir el acceso incondicional a recursos en especie como la sanidad, la educación, la vivienda o la energía, entre otros, con la misma mirada. Finalmente, conviene señalar que uno de los autores citados, John Rawls (1988), se mostró abiertamente contrario no al principio de incondicionalidad, sino, en concreto, a la propuesta de la renta básica. 
se puedan ensamblar caprichosamente, como en el lecho de Procusto, forzándolas a golpe de martillo o a hachazo limpio, es decir, dejándolas bajo el peso de la arbitrariedad ajena-.

En Ciencias Sociales, quizás desde la época de Adam Smith y Karl Marx (Casassas, 2010), estos repartos de tareas más atentos a la naturaleza y vocaciones de cada cual se caracterizan como procesos de división no social, sino técnica del trabajo: de lo que se trata es de que, sin negar la evidencia de que no siempre estaremos autorrealizándonos en grado sumo y de que hasta tendremos que asumir ciertas dosis de tareas para nada deseadas -a ello nos dedicaremos más adelante-, los procesos decisionales relativos al tipo de actividad, a su frecuencia, a su duración dentro de un día o de un ciclo vital y al modo en que se lleva a cabo -lo que incluye el lugar, las formas organizativas y la creación de grupos humanos para su realización- sean procesos decisionales a los que todos se vean invitados: ¿cómo decidimos entre todos cómo empleamos las propensiones y capacidades que todos atesoramos?

Pues bien, para que ello sea así, hemos de situamos en escenarios sociales en los que las tareas y actividades asignadas pueden entenderse como encargos recíprocos e iterados en los que todas las partes implicadas -quienes encargan y quienes hacen suyo el encargo en cuestión, sean actores individuales o colectivos- comprenden la naturaleza, el contenido y el sentido de la tarea que asumen, por un lado, y, por el otro, aceptan y comparten las razones y los procedimientos a través de los cuales terminan comprometiéndose con ella -y reservando otras tareas y cometidos para otras personas o colectivos- ${ }^{5}$. En este sentido, una vida social - un mundo del trabajo, remunerado o no- con procesos no arbitrarios de asignación de responsabilidades ha de ser un mundo que incorpore las restricciones institucionales necesarias -empezando, nuevamente, por una renta básica que nos proteja ante la posibilidad de decisiones heterónomas- para que se pongan en funcionamiento mecanismos de coordinación que, unidos a la acción de filtros epistémicos, hagan aflorar decisiones justas y eficaces en punto a resolver el problema de la distribución social de la actividad humana, todo ello en el seno de escenarios de interacción co-instituidos por todas las partes como algo cercano a lo que Antoni Domènech (1995) denominó "comunidad de juicio normativo"6.

5 En otras palabas, lo que se está planteando aquí es la necesidad de impugnar la fictio iuris propia del liberalismo doctrinario postnapoleónico, que asume que los individuos firman contratos libres y voluntarios por el "simple" hecho de que son iguales ante la ley (Domènech, 2004). Como he escrito en otro lugar (Casassas, 2018), para que un contrato sea un contrato, debe ser un verdadero (con)trato, esto es, un acuerdo o trato entre auténticos pares, entre actores sociales civilmente semejantes, con el objetivo de instituir algo en común -una relación de trabajo, sin ir más lejos-. No hay encargos libremente concebidos y aceptados por las partes sin los mecanismos necesarios - una renta básica, entre ellos- para escenarios de negociación en condiciones de "parigualdad" -de igualdad entre pares- o, en términos kantianos (Bertomeu, 2017), de "reciprocidad en la libertad externa".

6 Nótese que, en este sentido -y nos situamos ahora en otro plano de análisis, si bien estrechamente relacionado con lo que venimos discutiendo-, puede afirmarse que los deberes fiduciarios del Estado para con todos sus ciudadanos no se aplican solamente a la relación entre el Estado y cada ciudadano, sino también a la relación entre todos los que son ciudadanos. Y esto último implica que dicho deber fiduciario del Estado ha de traducirse en ciertas garantías que fomenten la inviolabilidad de la libertad y de los intereses de los ciudadanos, beneficiarios de la responsabilidad del Estado. De este modo, las garantías dimanantes del deber fiduciario del Estado, que consolidan verdaderos derechos constitutivos de ciudadanía, no tienen que ver sólo con la relación ciudadano-Estado -por ejemplo, el derecho a no ser torturado-, sino, también, con las relaciones privadas entre ciudadanos, empezando por el derecho a no vivir bajo el dominio de otro. Asimismo, estos derechos no tienen por qué garantizarse sólo mediante la potencial revisión judicial de cada acuerdo privado, sino también mediante arreglos institucionales -políticas públicas incluidas- que promuevan ex-ante, incondicionalmente, la 
Situados en este punto, podemos realizar un paso más y formularnos otra pregunta, sin duda menos abstracta: ¿a través de qué medios puede la renta básica abrir las puertas a toda esta "economía política de los encargos recíprocos”? ¿En qué sentidos concretos puede el poder de negociación asociado a la incondicionalidad situarnos en esta senda? Tres son los recursos que una renta básica puede otorgar a la ciudadanía: tiempo, propensión al riesgo y crédito (Casassas, 2018) 7 .

En primer lugar, la renta básica permite disminuir la urgencia de los "desesperados". Recordemos que Smith nos decía que proceden los desposeídos "con el frenesí y la extravagancia propios de los desesperados", todo ello porque "tienen la necesidad [...] de someterse para no carecer de los medios de subsistencia, [pues] a largo plazo, tanto el trabajador como el patrono se necesitan mutuamente, pero con distinta urgencia" (1981, 84-5). Y un manejo del tiempo con menores niveles de urgencia y ansiedad permite decisiones epistémicamente mejores y socio-institucionalmente más justas porque descansan en procesos negociadores más equilibrados: es sabido que la capacidad de "resistir", de "aguantar pulsos" a lo largo del tiempo constituye uno de los factores explicativos del poder de negociación de agentes sociales en liza.

En segundo lugar, la renta básica nos faculta para explorar sin temores opciones alternativas que impliquen ciertas dosis de riesgo. En efecto, esa posibilidad de (amenazar con) "salir" cuando la relación social no nos resulte satisfactoria requiere la presencia de recursos incondicionales que actúen a modo de red de salvación en caso de infortunio y caída. Nuestro poder de negociación depende de forma crucial de que, en escenarios de disputa e incertidumbre, contemos con la propensión a tantear dichos escenarios alternativos.

En tercer lugar, la renta básica debe entenderse también como "derecho al crédito", siempre en un sentido doble del término: por un lado, "crédito" como flujo constante de recursos financieros -la renta básica ha sido presentada como un proceso de universalización de los famosos "microcréditos", proceso que, además, libera a los beneficiarios de la discrecionalidad del prestamista, por bienintencionado que éste sea (Barrowclough, 2018)-; y, por el otro, "crédito" como "confianza social" que nos damos recíprocamente, como exhortación colectiva a que cada individuo o grupo ponga en movimiento sus propios proyectos, si hace falta a tientas y a partir de sistemas de ensayo y error que puedan exigir sucesivas oportunidades -como se ha visto antes, constituye ésta una posibilidad que ya existe, si bien queda reservada a unos pocos-.

Sea como sea, este hincapié en la cuestión del poder de negociación asociado a la incondicionalidad en el acceso a los recursos no aspira sino a recuperar el vínculo entre libertad y propiedad, entendida ésta como control de recursos, que ha sido central en la tradición republicana: pensemos en la trascendencia del acceso a la tierra en las alas izquierdas de las revoluciones francesa y norteamericana de finales del XVIII y en la forma en que ello fue heredado, debidamente reinterpretado, por el grueso de los socialismos, que vieron en el "benéfico sistema republicano [esto es, cooperativo] de la asociación de productores libres e

inviolabilidad de los intereses de los ciudadanos: el derecho a la vivienda o la presencia de un salario mínimo y de una renta básica, entre muchos otros. Agradezco a David Guerrero las esclarecedoras conversaciones que han permitido (co)elaborar esta idea.

7 Este análisis de los factores determinantes del poder de negociación sigue de cerca el ofrecido por Jon Elster (2007). 
iguales" al que se refirió Marx ${ }^{8}$ una forma de actualizar para el mundo industrial el proyecto de "civilización de la vida social" a través de la garantía del derecho a la existencia que el republicanismo democrático había traído siempre de la mano (Domènech, 2004).

Bien mirado, el proyecto de la renta básica se inscribe en esta tradición y permite retomar el espíritu político que inspiró el criterio de distribución que el propio Marx, en su Crítica del Programa de Gotha, sugirió para pensar sociedades instituidas en común. En efecto, gracias al poder de negociación por ella obtenido, la renta básica ha de favorecer que cada cual tienda a obtener "de acuerdo con sus necesidades" - esto es, que cada cual logre hacerse con los recursos y mecanismos para tirar adelante una vida escogida-, lo que, casi como subproducto, puede ayudar también a que cada cual pueda ir aportando "de acuerdo con sus capacidades" -en efecto, cada cual, desarrollando esos proyectos de vida propios, puede tender a externalizar (parte de) sus capacidades y, por ende, ofrecer a la comunidad (parte de) aquello que lleva dentro, que gusta de practicar y de lo que es verdaderamente capaz-.

Por ello, aspirar hoy a la liberación en el trabajo pasa por reivindicar la capacidad de negociar y obtener una "vida pluriactiva" (Gorz, 1998) que, como indica el término, acoja actividades de muy diversa índole -remuneradas por los mercados, pero también de cuidados, de formación, de participación cívico-política, de creación artística, de ocio, etc.--, lo que exige la presencia de una base material incondicionalmente garantizada que nos mantenga a salvo de cualquier forma de chantaje o coacción y que nos empodere para proponer $-\mathrm{y}$, si es preciso, forzar- unos repartos de "los trabajos", en plural, que respeten y aun promuevan los deseos y aspiraciones individuales y colectivos (Casassas, 2020b).

\section{Derecho a la existencia y bases materiales de la cooperación social}

Volvamos al centro social ocupado; al hogar cualquiera; a la cooperativa del sector agroalimentario; a la sociedad anónima en el ámbito de las nuevas tecnologías; al establecimiento comercial con diez trabajadores a sueldo; a la asamblea de barrio; a la revista y al proyecto editorial colectivo; al sector del agua o de la energía; y pensemos también en las comunidades aldeanas de la Europa tardomedieval y preindustrial; o en economías y sociedades enteras de este Antropoceno marcado por una profunda crisis eco-social que necesita una urgente respuesta política. En todos estos entornos y realidades, ha sido y es necesario concebir y poner en circulación formas de gestión de una interdependencia que se nos muestra como una realidad inapelable. Se asiente en lógicas y prácticas civilizadas y democratizadoras o cabalgue a lomos del despotismo y la barbarie, dicha interdependencia está ahí: un mundo en el que un sinnúmero de atomizados Robinson Crusoes se afanen por vivir en la absoluta autosuficiencia -de este distorsionado modo presenta la didáctica de la teoría económica la historia del náufrago de Defoe- constituye, en el mejor de los casos, un mito ilusorio.

Y lo interesante en este punto es que podemos referirnos a toda una miríada de mecanismos para, una vez reconocida, regir esa esencial interdependencia de la vida social: pensemos en las formas de socialidad que estructuraban y gobernaban los entornos y recursos comunes propios de comunidades aldeanas y distritos enteros en esa Europa preindustrial

8 Citado por Domènech $(2004,125)$. 
a la que nos hemos referido (Gauthier, 2017; Thompson, 2019); o en la economía política y las "costumbres en común" que vertebran también, ayer y hoy, redes de apoyo mutuo en clave feminista; o en el reparto de tareas que hace posible la continuidad del centro social ocupado de nuestro ejemplo; y pensemos también en los dispositivos, tantas veces desdemocratizadores -luego lo veremos-, a través de los cuales se asegura, bajo el capitalismo, que nada necesario -e innecesario también- quede sin hacerse. Justos o no, humanos o deshumanizadores $-\mathrm{y}$ hasta sangrientos-, tales mecanismos son el fiel reflejo de una consciencia compartida con respecto a la necesidad de arbitrar "algo" que, repartiendo responsabilidades, permita la vida en comunidad -la vida humana, en última instancia-.

Pero un momento. ¿Qué ocurre si, al tiempo que participamos de dicha consciencia, nos topamos con dispositivos como la renta básica -o, también, una sanidad pública plenamente universal e incondicional-, que apunten sin titubeos a la necesidad de que nos hagamos con recursos independientes de nuestra participación en la vida social y comunitaria? ¿Podríamos estar quebrando la estabilidad reproductiva de una sociedad que, para existir, necesita asegurar el concurso de todos en su cuidado? En los términos utilizados hace un instante: ¿puede que en un mundo con recursos universales e incondicionales llegue a ocurrir que algo $-\mathrm{o}$ mucho- necesario quede sin hacerse? Vayamos paso a paso.

Hay una estrofa de "La Internacional" que puede resultarnos útil para analizar esta cuestión. Dice así: "Basta ya de tutela odiosa, / que la igualdad ley ha de ser: / 'No más deberes sin derechos, / ningún derecho sin deber'". Parece que, en una sociedad justa, no hay derechos sin deberes: hay una interdependencia que nos acoge y quienes moramos en dicha sociedad justa, en entornos (re)productivos y espacios sociales democratizados, tenemos la obligación de hacernos cargo del cuidado y reproducción de esa interdependencia que nos cobija "[lejos] ya de tutela odiosa”. Si es así, ¿pueden llegar a existir "obligaciones incondicionales” que deban acompañar el "derecho incondicional a recursos" que se discute en estas páginas?"

Ahora bien, conviene evitar poner el carro delante de los bueyes: ¿realmente vivimos hoy, $y a$, en el seno de una "interdependencia que nos acoge" y que lo hace "[lejos] de tutela odiosa"? ¿O las grandes mayorías sociales se hallan sometidas a un tipo de interdependencia (capitalista) que las desposee de herramientas para una vida autónoma? En términos mucho más concretos: ¿qué tipo de reciprocidad se puede exigir a un trabajador destruido por el cepillo de la precariedad y reducido a la categoría de "suplicante" de pedazos de empleo y de añicos de subsidio, de "suplicante" de una vida hecha trizas en entornos socioeconómicos reducidos a cenizas (Casassas, 2020b; Standing, 2012)? ¿Cómo dotar la reciprocidad de sentido?

Seguramente, de lo que se trata en primera instancia -y seguimos sirviéndonos de "La Internacional" 10 , es de "hacer que el tirano caiga", es de dotarnos de herramientas para

9 César Rendueles (2019), quien para nada se muestra por principio contrario a la propuesta de la renta básica, sugiere que prestemos la debida atención a esta posibilidad. A su vez, un Stuart White que, con el tiempo, ha ido acercándose cada vez más a la lógica "incondicionalista" de la renta básica, sacudió el debate sobre dicha propuesta con un libro en el que planteaba que la ciudadanía económica se asentaba en derechos, pero también en obligaciones (White, 2003).

10 Al fin y al cabo, este himno contiene intuiciones ético-políticas centrales en unas tradiciones emancipatorias contemporáneas que han tendido a concebir la reciprocidad en el trabajo como el cemento de una sociedad justa. Este artículo aspira a alimentar una cultura crítica con respecto a las formas que puede tomar la domina- 
lograr decir "basta" a cualquier forma de "tutela odiosa" que podamos hallar en el centro de trabajo, en el hogar, en sectores productivos y economías enteras, etc. Sólo cuando nos sentimos invitados a formar parte (y a gozar de los frutos) de una comunidad así entendida, sólo cuando podemos sentirnos (en la senda que conduce al acto de quedar) liberados de relaciones sociales que destruyen nuestra autonomía y, con ella, las posibilidades de una vida digna, podemos plantearnos con pleno sentido cuidar de un mundo efectivamente hecho y disfrutado en común ${ }^{11}$. Si no, tales "cuidados" corren el peligro de convertirse en (¿nuevas?) formas de servidumbre ${ }^{12}$.

Así lo vio el ala izquierda de la Revolución Francesa, en la que sobresalían figuras como la de Thomas Paine, uno de los primeros en incardinar la propuesta de la renta básica en el republicanismo democrático-revolucionario moderno (Bosc, 2016), y Robespierre, quien dejó meridianamente claro que no había generalización de relaciones de parigualdad posible -en último término, no había república posible- si, de modo prioritario, no se garantizaba el inalienable "derecho a la existencia" de todos cuantos estuvieran llamados a formar parte de la república en cuestión. "La primera ley social es [...] la que garantiza a todos los miembros de la sociedad los medios de existir. Todas las demás están subordinadas a esta" -aseguró el revolucionario francés ante la Convención (Robespierre, 2005, 157)-. ¿Por qué? Porque ese "derecho a la existencia", inalienable y universalmente garantizado ex-ante por el mero hecho de formar parte de la sociedad humana, era y es lo que puede evitar el riesgo, señalado por Rousseau tres décadas atrás, de que haya ciudadanos tan pobres como para verse impelidos a venderse a terceros (Goodhart, 2007), y, de este modo, lo que puede consolidar

ción social en el mundo del trabajo, para que, sin que tengamos que renunciar a ella, esta vieja idea de "reciprocidad en el trabajo" pueda ser simbólica y normativamente resignificada e institucionalmente reencauzada.

11 Ello no significa que en entornos bárbaros no podamos alimentar deberes u obligaciones "morales" para con nuestros semejantes: ¿acaso no nos sentimos moralmente obligados a cuidar, por ejemplo, de nuestros abuelos bajo un capitalismo que tiende a dejarlos sin pensiones dignas y, a nosotros, sin recursos con que sostenerlos adecuadamente? ¿Acaso quienes se encontraban encerrados en Auschwitz no sentían la necesidad de "obligarse" a cuidar de quienes padecían a su lado? Sin embargo, conviene distinguir entre la observancia de estas "obligaciones morales" entre actores privados y el sinsentido que supondría -y tan a menudo supone- la exigencia político-institucional de respetar "deberes" y "obligaciones institucionalizadas" en contextos -empresas, hogares, mercados, etc.- en los que se nos ha privado de la capacidad y del derecho de co-instituir la interacción social. ¿O acaso estamos obligados a respetar solícitamente los “deberes” impuestos por los carceleros de Auschwitz o por quienes rigen los mercados de trabajo a golpe de despotismo institucionalizado?

12 Sin embrago, resulta importante insistir en el carácter dinámico que adquiere esta tarea de creación y reproducción de las condiciones materiales de una liberad incondicionalmente garantizada. Ni el mundo es binario -no es cierto que nos tengamos que hallar o bien bajo condiciones de "pleno respeto" hacia la autonomía de las partes, o bien sumidos en la ilibertad más extrema- ni adquirimos el sentido de pertenencia a una comunidad que nos acoge como miembros de pleno derecho sólo cuando estamos ya en ella. Como he sugerido en otro lugar (Casassas, 2020b), también el camino del empeño colectivo por lograr esas "condiciones-materiales-dela-libertad-incondicionalmente-garantizadas" o, si se prefiere, también la "mera" resistencia a la desposesión capitalista, resistencia tantas veces enrevesadamente dificultosa por hallarse asentada en condiciones de profunda precariedad (in)material, puede convertirse y, de hecho, se convierte a menudo en el semillero de toda una cultura de la cooperación social que vaya prefigurando e incluso generando espacios para formas de socialidad abiertamente democráticas, postcapitalistas, que deseemos y convenga cuidar, sostener. Sin lugar a duda, el propio acto de resistir la "tiranía", la "tutela odiosa", adquiere ya un poder instituyente de alternativas societarias que no puede ser desatendido. 
las bases materiales y simbólicas de una interacción social asentada en relaciones no de subordinación de los muchos a los pocos, sino de cooperación efectiva entre todas las partes ${ }^{13}$.

Pero volvamos a los niveles de concreción de todas estas cuestiones a los que obliga el interrogante anteriormente abierto: ¿existe la posibilidad de que, en un mundo en el que se acceda a recursos de manera incondicional, llegue a ocurrir, precisamente por ello, que algo -o mucho- necesario quede sin hacerse? Aterricemos al máximo: ¿quién se encargará de limpiar las letrinas del centro social autogestionado? ¿A cargo de quién correrán las tareas menos creativas en la sociedad anónima del ámbito de las nuevas tecnologías? ¿Quién tomará acta de las reuniones de la asamblea de barrio y quién recogerá las sillas? ¿Y sobre los hombros de quién o quiénes recaerán las tareas de cuidados que, por la razón que sea, resulten menos gratas? ¿Cómo asegurarnos de que las tareas socialmente necesarias se lleven a cabo?

Cuatro posibilidades se abren ante nosotros. Las tres primeras son de recibo. La cuarta, en ningún caso, pues hace volar por los aires los cimientos de la libertad efectiva. La primera consiste en que, de forma descentralizada o distribuida en el espacio y a lo largo del tiempo, y siempre gracias al poder de negociación conferido por el carácter incondicional de esos recursos otorgados ex-ante, operen mecanismos que incentiven a determinados (grupos de) actores a hacerse cargo de esas actividades socialmente necesarias: salarios más altos, mejores usos del tiempo, etc. (Wright, 2006). La segunda consiste en que, ante la evidencia de una resistencia generalizada a la realización de determinadas tareas por parte de actores incondicionalmente empoderados, ciertos sectores productivos tiendan a emprender procesos de automatización que hagan innecesaria la mano de obra humana. La tercera consiste en que, en un contexto de rechazo unánime de tareas socialmente necesarias y, también, de imposibilidad técnica de recurrir a la robotización, por lo menos en el corto o el medio plazo, se abran procesos público-comunes de deliberación democrática para el reparto equitativo, entre todos los miembros de la comunidad, sin privilegios, de las proporciones o dosis de trabajo socialmente necesario que se estime que corresponden a cada cual ${ }^{14}$. Finalmente, la cuarta posibilidad, que más que una "posibilidad" constituye la tónica dominante en las

13 Nótese que un "padre fundador" del pensamiento social contemporáneo como Adam Smith anduvo por los mismos derroteros. Las altas dosis de división del trabajo propias de las sociedades modernas -afirma el escocés- nos convierten a todos en sujetos interdependientes, en actores interconectados a través de unas prácticas comerciales que nos permiten ir satisfaciendo la diversidad de necesidades presentes en la sociedad. Por ello, habida cuenta de que todos nos necesitamos a todos, es preciso que todos nos comprometamos con la tarea de garantizar políticamente la presencia de una verdadera comunidad de semejantes, nunca de actores sometidos a la discrecionalidad ajena, y es preciso hacerlo garantizando posiciones de invulnerabilidad social a todas las partes (Casassas, 2010). Sólo así podemos hablar de "cooperación social” en un sentido no huero del término.

14 Bien mirado, la institución democrática de estos repartos equitativos del trabajo socialmente necesario puede ser concebida como otra de las obligaciones fiduciarias de los poderes públicos para con los ciudadanos. Ni que decir tiene, en este punto resulta crucial que tales poderes público-comunes, verdaderos agentes fideicomisarios del pueblo soberano, actúen férreamente sometidos a todo tipo de mecanismos de control y escrutinio popular que eviten la invasión despótica del ámbito de existencia social de la ciudadanía. Para una revisión histórica y conceptual de la libertad política como resultado de un fideicomiso, véanse Domènech (2004) y Mundó (2017). A su vez, Stuart White $(2003,171)$ da cuenta de aquellos autores -Ronald Dore o el André Gorz de la década de 1980 - que han sugerido un "servicio ciudadano como complemento de una renta básica". Nótese, sin embargo, que, así como tales autores presentan dicho "servicio ciudadano" como algo que debe acompañar la renta básica bajo cualquier circunstancia, en este ensayo se afirma que ha de ser considerado sólo en caso de que queden 
sociedades capitalistas, consiste en permitir que operen mecanismos de desposesión de las grandes mayorías sociales que hagan que éstas, carentes de recursos que garanticen su existencia, terminen viéndose sistémica y sistemáticamente obligadas a hacerse cargo de esas tareas desagradables que, en principio, nadie desea hacer-volvemos aquí, pues, a un escenario de abierta división social del trabajo-. El mostrar por qué estas formas de "interdependencia a punta de pistola" no son normativamente deseables y a través de qué vías el acceso universal e incondicional a recursos como el que proporciona una renta básica ayuda a evitar estas liberticidas relaciones sociales constituye uno de los objetivos centrales de estas páginas. De hecho, la capacidad de instituir combinaciones de las tres primeras opciones y de sortear la cuarta se halla estrechamente vinculada al ideal de democracia, que exige el sometimiento de la vida económica al control popular, que hemos hecho nuestro desde el principio. Veamos en qué sentidos y con qué implicaciones y concluyamos.

\section{Producción social de la riqueza y nacionalización de la vida económica: ¿qué papel para la renta básica?}

Este texto tiene como telón de fondo la idea según la cual la riqueza es un producto social que resulta de esfuerzos colectivos presentes y pasados entrelazados de muy diversas formas, lo que tiene que ver con importantes dosis de inversión pública directa y, también, con la sedimentación de recursos (in)materiales de herencia común (Mazzucato, 2019). De este modo, la riqueza termina en manos de unos y no de otros como consecuencia de todo tipo de azares y circunstancias sociales. Si esto es así, distribuir esa riqueza a través de dispositivos como una renta básica, entre otros, no es sino una inversión colectiva para consolidar, ahora y a largo plazo, la libertad efectiva de todos. De ahí, también, que autores como James Meade (1964) o, actualmente, Yanis Varoufakis (2016) hayan propuesto un "dividendo social" que permita el acceso universal e incondicional, a partes iguales, al fruto de esa empresa colectiva que constituye la generación de riqueza. Al fin y al cabo, ello es lo que ha de permitir someter el grueso de la vida económica a control democrático o, si se prefiere, nacionalizarla.

Pero ¿qué sentido tiene en este punto hablar de "nacionalización" de la vida económica? Ante todo, conviene advertir que nacionalizar la vida económica para nada equivale a someterla a los dictados discrecionales de una casta burocrática estatal poco dispuesta a rendir cuentas. La "nacionalización" de la vida económica ha de asociarse a la capacidad de influencia y de control democrático, por parte del grueso de la ciudadanía, empezando por sus sectores populares, sobre los procesos decisionales relativos a la configuración de las relaciones económicas y sociales ${ }^{15}$. En este sentido, formas de nacionalización hay muchas. Aquí nos centraremos en tres.

En primer lugar, la nacionalización de la vida económica puede pasar por la estatalización de ciertos ámbitos de actividad -el agua, la energía o la vivienda, entre otros-, siempre y cuando tales instancias y procedimientos estatales estén sometidos al escrutinio y al

tareas necesarias por hacer o, en otros términos, en caso de que el producto social resulte insuficiente para cubrir universalmente las necesidades básicas de la vida.

15 Interesantemente, el Oxford English Dictionary, basándose en fuentes decimonónicas, asocia "nacionalización” a "la acción de poner tierra, propiedades, industrias, etc. bajo el control de la nación [no necesariamente del Estado]". Antoni Domènech tuvo la generosidad de regalarnos inspiradoras conversaciones privadas sobre esta cuestión. 
gobierno por parte del conjunto de la ciudadanía -nuevamente, asoma aquí la visión de las instituciones públicas como "meros" agentes fiduciarios del pueblo soberano-. En segundo lugar, y por paradójico que pueda parecer, nacionalizar la vida económica puede equivaler a instituir derechos de propiedad -empezando por la privada- entendidos también como relaciones fiduciarias: el propietario de los recursos puede sacar provecho de ellos, pero se halla constreñido por obligaciones para con el resto de conciudadanos, quienes han de poder exigirle que su disfrute del recurso sea compatible con la satisfacción de las necesidades de la colectividad y con la transmisión en buen estado del recurso en cuestión a las generaciones por venir ${ }^{16}$. En tercer y último lugar, nacionalizar la vida económica puede significar, también -ninguna de las tres posibilidades son incompatibles entre si-, conferir recursos incondicionales -una renta básica, por ejemplo- que otorguen "poder social" (Wright, 2014) a todos y cada uno de los individuos y grupos que constituyen la comunidad, para que sean éstos quienes, de forma descentralizada y a través de procesos de negociación en los que puedan "aguantar la mirada" de aquellos con quienes interactúan (Casassas, 2018; Pettit, 2012), ejerzan una capacidad de influencia y control sobre la conformación de las relaciones sociales, empezando por las (re)productivas, que les permita convertirse en verdaderos coautores del mundo en el que moran.

Bien mirado, se apunta aquí a la necesidad de reinterpretar contemporáneamente el viejo ideal republicano-socialista de la "propiedad o control colectivo de los medios de producción" -y de "reproducción", conviene añadir-, lo que no significa otra cosa que el ejercicio de la capacidad, al alcance de todos -de ahí que hablemos de control "colectivo"-, de codeterminar, ahora y a lo largo del tiempo, la naturaleza y el funcionamiento de los espacios y procesos sociales donde producimos bienes materiales e inmateriales, donde reproducimos la vida, donde tomamos decisiones sobre cómo vivir en común (Casassas, 2018). Poner esta capacidad al alcance de todos, en parte gracias a la presencia de la renta básica, equivale a lograr niveles relevantes de esa democracia (económica) como capacidad cuatripartita que se ha presentado al inicio de esta reflexión.

\section{Referencias}

Barragué, B. (2017), Desigualdad e igualitarismo predistributivo, Madrid: Centro de Estudios Constitucionales.

Barrowclough, D. (ed.) (2018), The Ins and Outs of Inclusive Finance: Some Lessons from Microfinance and Basic Income, Nueva York y Ginebra: UNCTAD.

Bertomeu, M.J. (2017), «Pobreza y propiedad. ¿Cara y cruz de la misma moneda? Una lectura desde el republicanismo kantiano», Isegoría: Revista de Filosofía Moral y Política, 57, pp. 477-504.

Birnbaum, S. y De Wispelaere, J. (2016), «Basic Income in the Capitalist Economy: The Mirage of 'Exit' from Employment», Basic Income Studies, 11(1), pp. 61-74.

Birnbaum, S. y De Wispelaere, J. (2020), «Exit strategy or exit trap? Basic income and the 'power to say no' in the age of precarious employment», Socio-Economic Review, disponible en https://academic.oup.com/ser/advance-article/doi/10.1093/ser/mwaa002/5727916.

16 Para un análisis sistemático de la concepción de la propiedad como relación fiduciaria, véase Mundó (2018). 
Bosc, Y. (2016), La terreur des droits de l'homme. Le républicanisme de Thomas Paine et le moment thermidorien, París: Éditions Kimé.

Casassas, D. (2010), La ciudad en llamas. La vigencia del republicanismo comercial de Adam Smith, Barcelona: Montesinos.

Casassas, D. (2016), «Economic Sovereignty as the Democratization of Work: The Role of Basic Income», Basic Income Studies, 11 (1), pp. 1-15.

Casassas, D, (2018), Libertad incondicional. La renta básica en la revolución democrática, Barcelona: Paidós.

Casassas, D. (2020a), «Pre-distribution, Basic Income, and the Institutions of Economic Democracy», mimeo.

Casassas, D. (2020b), «Libertad incondicional y trabajo libre en sociedades pluriactivas: ¿qué papel para la renta básica?», Pasos a la izquierda, 18.

Domènech, A. (1995), «Individualismo ético e identidad personal», en: Aramayo, R.R., Muguerza, J. y Valdecantos, A. (comps.): El individuo y la historia: Antinomias de la herencia moderna, Barcelona: Paidós, pp. 29-43.

Domènech, A. (2004), El eclipse de la fraternidad. Una revisión republicana de la tradición socialista, Barcelona: Crítica.

Elster, J. (2007), Explaining Social Behavior: More Nuts and Bolts for the Social Sciences, Nueva York: Cambridge University Press.

Gauthier, F. (2017), «Communauté villageoise», en: Rochfeld, J., Cornu, M. y Orsi, F. (dirs.): Dictionnaire des biens communs, París: PUF.

Goodhart, M. (2007), «'None So Poor That He Is Compelled to Sell Himself': Democracy, Subsistence, and Basic Income», en: Hertel, S. y Minkler, L. (eds.): Economic Rights: Conceptual, Measurement, and Policy Issues, Cambridge: Cambridge University Press, pp. 94-114.

Gorz, A. (1998), Miserias del presente, riqueza de lo posible, Barcelona: Paidós.

Gourevitch, A. (2014), From Slavery to the Cooperative Commonwealth: Labor and Republican Liberty in the Nineteenth Century, Nueva York: Cambridge University Press.

Gourevitch, A. (2016), «The Limits of a Basic Income: Means and Ends of Workplace Democracy», Basic Income Studies, 11(1), pp. 17-28.

Hacker, J. S. (2011), «The Institutional Foundations of Middle-Class Democracy», en: Policy Network (comp.): Priorities for a New Political Economy: Memos to the Left, Londres: Policy Network.

Harvey, D. (2003), El nuevo imperialismo, Madrid: Akal.

Hirschman, A. O. (1970), Exit, Voice, and Loyalty: Responses to Decline in Firms, Organizations, and States, Cambridge, MA: Harvard University Press.

Kenworthy, L. (2013), «What's Wrong with Predistribution», Juncture, 20(2), pp. 111-117.

Marx, K. y Engels, F. (1970) [1844-1845], La ideología alemana, Barcelona: Grijalbo.

Mazzucato, M. (2019), El Estado emprendedor. Mitos del sector público frente al privado, Barcelona: RBA.

Meade, J. (1964), Efficiency, Equality, and the Ownership of Property, Londres: George Allen \& Unwin. 
Mundó, J. (2017), «La constitución fiduciaria de la libertad política. (Por qué son importantes las coyunturas interpretativas en la filosofía política)», Isegoría: Revista de Filosofía Moral y Política, 57, pp. 433-454.

Mundó, J. (2018), «De la retórica absolutista de la propiedad al sentido común de la propiedad limitada», SinPermiso, 16, pp. 35-63.

O’Neill, M. y Williamson, T. (2012), Property-Owning Democracy: Rawls and Beyond, Oxford: Wiley-Blackwell.

Pettit, P. (2012): On the People's Terms: A Republican Theory and Model of Democracy, Cambridge: Cambridge University Press.

Rawls, J. (1988), «The Priority of Right and Ideas of the Good», Philosophy \& Public Affairs, 17(4), pp. 251-276.

Rawls, J. (2001), Justice as Fairness: A Restatement, Cambridge, MA: Harvard University Press.

Rendueles, C. (2019), «Afavorencontra de la renta básica», Minerva. Publicación semestral del Círculo de Bellas Artes, IV época, 32, pp. 21-23.

Robespierre, M. (2005) [1792], «Sobre las subsistencias y el derecho a la existencia», en: Robespierre, M: Por la felicidad y por la libertad. Discursos (ed. Y. Bosc, F. Gauthier y S. Wahnich), Barcelona: El Viejo Topo.

Smith, A. (1981) [1776], An Inquiry into the Nature and Causes of the Wealth of Nations (ed. R. Campbell y A.S. Skinner), Indianapolis: Liberty Fund.

Standing, G. (2012), El precariado: una nueva clase social, Barcelona: Pasado \& Presente.

Thomas, A. (2016), Republic of Equals: Predistribution and Property-Owning Democracy, Oxford: Oxford University Press.

Thompson, E.P. (2019) [1991], Costumbres en común. Estudios sobre la cultura popular, Madrid: Capitán Swing.

Varoufakis, Y. (2016), «The Universal Right to Capital Income», Project Syndicate, disponible en https://www.project-syndicate.org/commentary/basic-income-funded-by-capitalincome-by-yanis-varoufakis-2016-10?barrier=accesspaylog.

White, S. (2003), The Civic Minimum. On the Rights and Obligations of Economic Citizenship, Oxford: Oxford University Press.

White, S. (2012), «Property-Owning Democracy and Republican Citizenship», en: O’Neill, M. y Williamson, T. (comps.): Property-Owning Democracy: Rawls and Beyond, Oxford, Wiley-Blackwell, pp. 129-146.

White, S. (2020), «Labour, Capital and Commons: Three Sites of Predistribution», en: Merrill, R. (comp.): Predistribution, en prensa.

Widerquist, K. (2013), Independence, Propertylessness, and Basic Income: A Theory of Freedom as the Power to Say No, Nueva York: Palgrave Macmillan.

Wright, E.O. (2006), «Two redistributive proposals - universal basic income and stakeholder grants», Focus, 24(2), pp. 5-7.

Wright, E.O. (2014), Construyendo utopías reales, Madrid: Akal. 
